\title{
The "Static" and "Dynamic" Design Verification Stages of the Lean Development Process: Automotive Industry
}

\author{
F. Ali Paker \\ Industrial Design Department of Istanbul Technical University, Istanbul, Turkey \\ Email: pakerali@gmail.com
}

How to cite this paper: Paker, F.A. (2020) The "Static" and "Dynamic" Design Verification Stages of the Lean Development Process: Automotive Industry. World Journal of Engineering and Technology, 8, 74-91. https://doi.org/10.4236/wjet.2020.81008

Received: December 9, 2019

Accepted: February 14, 2020

Published: February 17, 2020

Copyright ( 2020 by author(s) and Scientific Research Publishing Inc. This work is licensed under the Creative Commons Attribution International License (CC BY 4.0).

http://creativecommons.org/licenses/by/4.0/

\section{Open Access}

\begin{abstract}
The design verification steps that take place in today's automotive industry, which constitute the values of each successive or simultaneous phase in the new product development process, create a complex structure with the inclusion of each new technology and discipline. Therefore, step by step, each design verification phase definition in the flow contains important phase transition measurements or approval tolerances that ensure the simplicity and continuity of vehicle development processes. In addition, classification of design verification stages within the framework of this study or evaluation in two classes (static and dynamic) is a new approach, but it is a synthesis with the analysis of the new product development process. The vehicle's basic structure, which constitutes the ergonomic and functional requirements of the vehicle in a static environment, takes into account the dynamic environment variables with crash or accident tests. Increasing new technology adaptations in the automotive industry have changed the new product development process that performs this function structurally and created the concept of design verification under consecutive or simultaneous process simplicity. From the autonomous driving to the use of alternative energy, possible accident scenarios and design verification phase transitions in the integration of parts and systems of the newly developed vehicle create a new structure that models and directs the lean product development process especially in the automotive industry in the coming days. In the lean product development process that takes place in the automotive industry, the design verification transition steps or the approval-control analysis of the development stages, which form a new and effective approach, are re-modeling the entire flow. Therefore, successful execution of design verification steps used in the control of new interdisciplinary product development phase transitions provides value creation. Within the scope of this study, the effectiveness of the static and
\end{abstract}


dynamic design verification steps, which are carried out in 5 global automotive companies included in the research, which constitute the stage transitions of the new product development process, has been measured. Apart from the design verification transition stages, the process variables that differ among the automotive companies involved in the research are excluded from the scope of this study. In other words, in field researches in the automotive industry, new vehicle design steps or basic engineering steps in the new product development process steps, while creating independent fixed variables, interdisciplinary collaborations, static and dynamic design verification transition stages they perform, or their sequence in the basic flow, is accepted as a dependent variable. Therefore, in the study, the positive effect of the automotive companies that included the static and dynamic design verification phase transition approvals in the lean product development process was investigated. Under the comparative analysis structure of the research, the effect of automotive companies, which accept international vehicle specifications as static design verification input, on market performance has been examined in depth. The detailed depth in the comparison analysis conducted under the second field studies of the study is due to the prediction of dynamic design verification stages to provide a high impact on the market performance, according to the static verification analysis. The new product development stages of the dependent variables were fixed and the flow-oriented "effect" of the independent variables in the basic process influenced by the design verification activities was analyzed under the new automotive industry company comparisons. In addition, the impact of the automotive design activities that make up the comparison analysis of the research on the scope of the lean product development stage and its effect on the basic process flow has been demonstrated competition-oriented. Therefore, sub-variables, options, criteria, results, which form a defined comparison problem, create basic test values that affect the problem.

\section{Keywords}

Design Verification Phases, Lean Development Process, Automotive Industry, Design Process

\section{Introduction}

Verification of new vehicle design with scientific methods in the new product development process, which is simplified, constitutes the basic market success of competing automotive companies. This approach envisages the determination of the product development processes existing in the companies, their simplicity within the framework of value creation, and the continuous improvement of these processes in line with changing customer needs and expectations [1] [2] [3] [4]. Therefore, measuring the positive effect of the increase in the number of design verification steps that constitute the internal phase transitions of the basic flow to the new product development process takes place under the criteria that 
are important in customer preferences. The technology performance structure of the new vehicle (alternative energy, usage range, autonomous driving level, etc./new product performance, product sales price, market share or market spread) effects directly the new product development process structure and product life cycle (product development phase number/design verification step transition approval-control analysis number). In addition, the design verification steps related to the development and testing process include backward adaptation studies for a given process size [5] [6] [7]. Environmental new technologies, innovation adaptations, developments and changes in the manufacturing industry, which are included in today's automotive industry, are gradually modeling the new product.

Increasing environmental and emission values in the international automotive industry have also changed the customer demand structure; technological possibilities and innovations have affected the processes of realizing new products. Lean product development specialties with different scientific approaches focus on largely proof-based experimental evidence among test models with different conditions, and demonstrate a result-oriented design verification approach away from complex and variable situations [8] [9] [10] [11]. Due to the process and technological changes, customer needs have improved, but have started to demand higher functionality and quality at the same rate, at a lower price [1]. Therefore, in the light of these developments, the global automotive industry is turning to interdisciplinary design verification steps that take an important place in value creation in order to meet the customer needs changing under heavy competition conditions with lean product development processes. In the automotive industry, the development of the concept of virtual design verification is transferred with qualitative knowledge; published research is divided into shorter periods [3] [5] [8] [12]. Comparatively, the vehicle presented by the automotive companies in the market to the new market is a decision problem that focuses on the design validation transition steps of the companies in the new product development process, which includes many criteria. In other words, the design verification process includes the approval-control and decision stages of alternative conceptual designs created according to the innovations targeted at the beginning of the project [1] [12] [13]. Therefore, not only the number of new product development stages, but also the new technology performance of the new product or the new product market spread is the most important factor to consider in this choice. Therefore, it is necessary to evaluate and prioritize the criteria in order to reach a systematic competence process selection among the criteria related to new technology and market spread that constitutes the new product in the research. The development, improvement or innovation gains of the process changes related to the new product design are inevitable [14]. Developing and designing near or far future vehicles in the automotive industry with today's new technologies creates possible complex structures under the integration of these technologies. These problem solutions reveal systematically step by step decision-making calculations (AHP), and approaches to verification 
of new designs.

As in Figure 1, the information contained in the rational analysis of the design or the repeated cycle of the synthesis of creativity has positive value [1] [2]. Therefore, physical or computer design simulations in the new product development process support the analysis of the basic flow and also the synthesis stages [2]. In this context, the concept of design validation includes "basic" and most important approaches of the design process [1] [13]. Each design verification step in the study evaluates the common interdisciplinary scientific concepts in the product development process and the different performances of the new product (Figure 1). Thus, in the product development process structures, verification and approval of various performance criteria of the new vehicle defined by flow specializations under the conditions of use constitute holistic approaches [1] [13] [14] [15].

Thus, in the product development process structures, verification and approval of various performance criteria of the new vehicle defined by flow specializations under the conditions of use constitute holistic approaches. Static validation limit values for vehicle design are included in the entire flow, from the initial conceptual style work of the new product development process to tipping and crash physical tests (Figure 1). Although the vehicle design verification parameters are more detailed in large-scale global automotive companies, these limits constitute the regional, technical, regulatory, limit values of international vehicle construction specifications (ECE, EEC, SAE, etc.) or vehicle-related systems. In the automotive industry, the competitive development of new vehicles creates dynamic conditions created by the new technology in addition to the limit values in the international specifications (Figure 1). Therefore, the market success, market spread or after-sales quality costs of the final new vehicle, the integration of the new adapted technology on the vehicle, together with the conditions of use together with the dynamic application values, show a direct proportioned approach.

The design verification steps involved in each phase transition of the new product development process question the possibility of an accident due to any error during the dynamic use of the vehicle under new vehicle functions:

- It checks the limits of developmental characteristics related to the current structural vehicle form under dynamic driving values (Weight, Material, Aerodynamics, Power, Engineering values, etc.).

- It creates parametric boundaries that form the driving continuity relationship of new technologies integrated on the new vehicle developed. (Speed, Range, Level/Zone, Fuel Cell Position-Volume-Cooling-Service, Autonomous Equipment GPS-Radar-Main Board X, etc.).

Over the accident scenarios, the new technologies integrated into the new vehicle developed, predict the limit values brought in a dynamic environment under the existing values in the application (dynamic impact of existing systems on new equipment). 


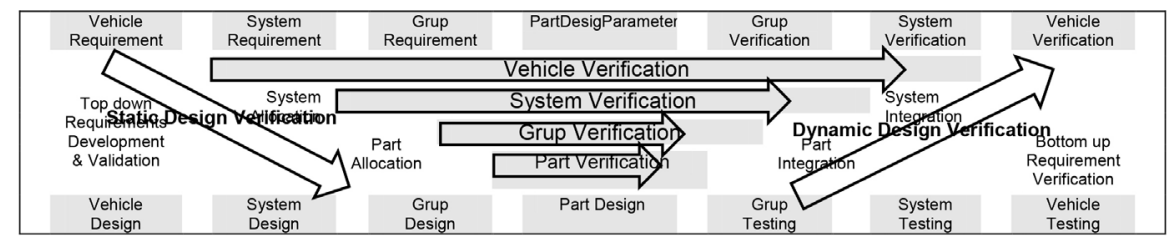

Figure 1. The "V" model for the design verification [1] [2] [16].

Under the ultimate innovation objectives of the newly developed vehicle, the initial creation of design validation limits, process efficiency and optimization are an important input for market spread in competition. This new structure guides the value creation under the design verification criteria of the critical tolerance and approval parameters that form the phase transition in the leaner product development process. Along with the advantages provided by the testing parameters in question, the reliability of the newly developed vehicle under these limits or the progress of the whole lean product during the verification process has become a preferred method for all stakeholders in the automotive companies involved in the field study. Therefore, when the flow of the study is examined: the relationship between the lean product development processes and the design verification and the effect size are determined in the next section under the AHP method, by automotive company comparisons. In the next Chapters 3 and 4 , static and dynamic design verification methods are comparatively modeled on the differences and similarities in automotive companies involved in field research. In Chapter 5, the final measurement and results are shared under AHP precision analysis.

At the beginning of the study, one-on-one interviews covering the product development process steps, stage cooperation structures and the definition of current disciplines in automotive companies in the field of application were carried out under a detailed field research. Therefore, in the light of this information, in the second field study in accordance with the comparison structure, AHP questionnaire was applied. In addition, a series of mutual interviews and consecutive AHP surveys conducted during the preliminary phase form the definitions in the application area of the research. With the AHP model, which is the method suitable for the analysis of qualitative and quantitative findings obtained from the field of application, the results were verified numerically and took its place in the last part of the research. Therefore, the research has been advanced from the beginning to the end with an approach to test the findings revealed in the previous stage in prints. The research was carried out under the use of systematic research methods, carried out with the employees of the automotive industry firms operating at the national and international level or having a global spread and working in the formation phase of the new product, within the framework of the defined application area.

\section{The Design Verification Phases of the Lean Development Process}

In the automotive industry, the design verification phase's transitions bring to- 
gether the basic design and engineering steps involved in the simplification of new product development process under the common denominator and provide the approval-control of innovations. Therefore, within the framework of innovations and new technologies: the effect or structural integration of the intended, systematic features (parts, detail, group basis) to the whole, expected from the new vehicle project, creates new variables in the product development process. Furthermore, all of the steps that demonstrate the compatibility or incompatibility of existing systems in structure or vehicle integration, where the new technology performs the expected behaviour's, are tested with interdisciplinary values in design verification steps.

Developing under new technologies, the holistic systems meet the design requirements fully, and it is important to decide that the outputs in each phase of lean product development are correct and that this is an important input for the continuation or success of the process. Therefore, the analysis steps in the relevant test and decision-making (AHP) flow constitute the design verification phase transitions in a repetitive structure throughout the process. When this definition is examined with a holistic approach: design verification phases transitions, all new product development process outputs are tested in the flow, it is determined in the research that the new vehicle affects the basic parameters that occur in parts and different disciplinary focus. Therefore, it is possible to design and validate the new vehicle on the basis of parts in the static environment with the use scenarios created in the dynamic environment and to define the process variables in the holistic approach.

Although this approach takes time-based and complex approaches during the lean product development process in the automotive industry, it becomes more defined with the concept of testing in the new design verification phase's transition. Basically, the purpose of the design verification transition steps is to identify possible defects found in the new automotive product developed and to take necessary corrective actions. Therefore, the planning and implementation of this process forms the basis of the lean product development process and the concept of value creation. The design verification transition testing steps, which were determined (AHP) in 5 automotive companies in the field study and carried out in the new product development process, emerged as a result of the rapid development of design and engineering software used today. This rapid development, together with the effective use of computer, CAD, CAE, CEA, etc., software, different disciplines in the new product development process, constitutes the tests in the "static" and "dynamic" environment reviews and software environments.

The hierarchical sequence for the alternative design verification process AHP selection problem at the beginning of the application is given in Figure 2. Basic AHP (Analytic Hierarchy Mathematical Model) decision problem is the productive process's automotive product; hence design verification stages choice, as a result of comparing the AHP criteria contained in the objective (Figure 2).

Figure 2, shows the AHP mathematical model which constitutes the comparison structure of the research. The study is planned as a comparison structure on 


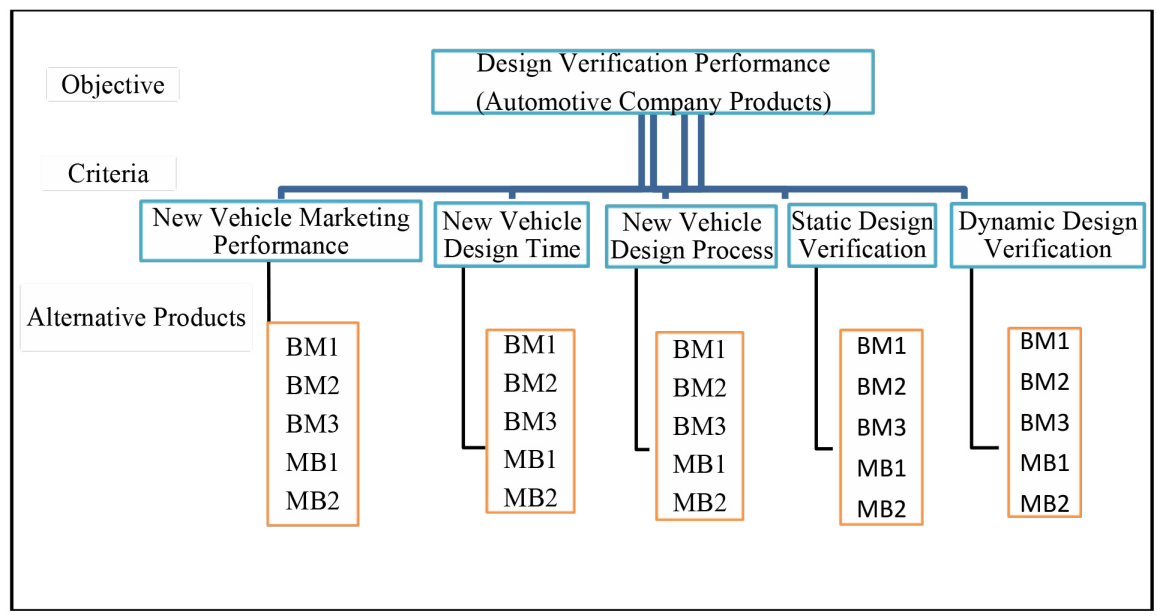

Figure 2. The "static" or "dynamic" design verification phases for AHP.

the design verification flow of automotive products in the application area, as constructed in AHP structure in Figure 2. In all 5 companies involved in the research carried out in the automotive industry, the design validation phase transitions in the new product development process include "static verification" (static status assessment) studies, while the use of CAE, CEA, CAD, etc., software tests in practice is considered as a "dynamic verification" method (Figure 2).

Review of the design verification transition steps ("static" and "dynamic", design verification studies): to examine the suitability of the technological function adapted to the vehicle developed under the adaptation of the new technology for effective use, to determine the deviations from possible accident scenarios and involves existing standards within the holistic structure assessments (Figure 3). Computer analysis software (virtual dynamic design verification steps), which include CEA, CAE, CAD, vehicle tests in the design verification transition steps, calculations under possible alternative accident scenarios, measure the response of functional behaviour's to the holistic structure in the dynamic environment expected from the new technology added to the new vehicle (Figure 3).

Figure 3, shows the design verification process schematically with the help of field research conducted under face-to-face interviews. Static design verification transition stages in automotive industry applications constitute product lifecycle propositions modelled in new product development process (Figure 3). In addition, the dynamic design verification approval stages in each phase transition of the lean product development process reveal only the limit verification parameters of the basic structure of the newly developed vehicle under possible accident scenarios. Static design verification stages in the new product development process; the new vehicle is being reviewed for compliance with international technical regulations/specifications (EEC, ECE, CE, SAE, etc.) or vehicle anatomy, ergonomics, comfort, and dynamic design verification under the accident, resistance, stress, safety, etc., strength tests.

Lean product development process, "static" and "dynamic", design verification stages: 


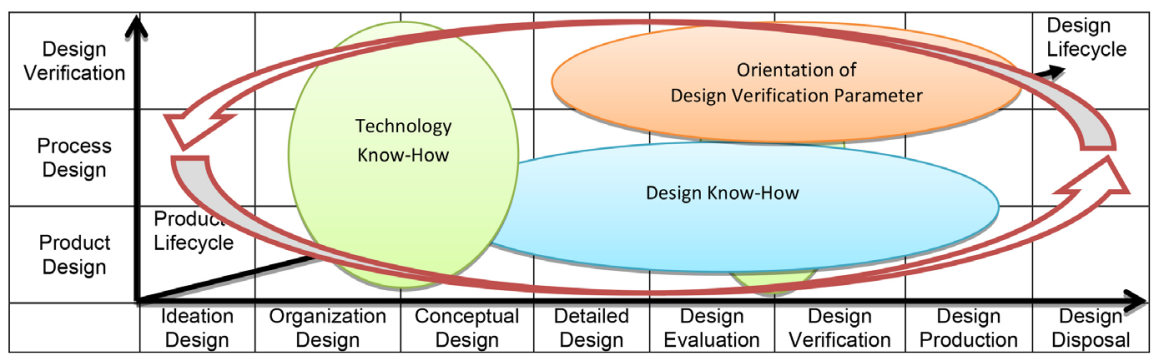

Figure 3. The products lifecycle verification (PLM) of new vehicle design [1].

- Under the new product lifecycle, all functions of the new menu or adapted technology work in accordance with the objectives,

- The formation of full, usable, testable definition limits and parameters of the basic functions in the holistic structure of the new vehicle,

- The dynamic environment of our design, new options, functional and verifiable,

- Adjusted new technology, the new vehicle design in dynamic environment under the accident scenarios envisaged the exact realization of the structure and the instantaneous response to the whole is measured,

If the innovations in the lean vehicle design stages are not reviewed step by step, step transitions, the deficiencies in the project targeted new vehicle functions or the contradictions of integration within the overall structure will either be unnoticed or will only emerge at advanced stages of the new product lifecycle.

Since the correction of the errors detected during the stages of the new vehicle design will result in longer corrective activities, the risk of project costs increases with the prolongation of the lean product development process. In the early stages of lean product development, one of the objectives of the review of the new design is to determine whether innovation or new technology integration contains sufficient detail or function to perform realization tests within the holistic new structure. A step-by-step review of the newly developed vehicle at the initial static design verification stages creates an early test of the impact on the whole of each new technology or function added to the new vehicle. The objective of the static validation tests in each phase, transition is the logical errors in the technology integration, the situations in which the developed autonomous or manual function does not meet the dynamic validation test or international specification standards, or the structural adequacy state (defined response of the predicted variables or the response of undefined, unpredictable variables) at the beginning of the process.

Although virtual and static design verification studies on the new vehicle, which constitute the initial steps of lean product development processes, have an important role in error prevention and detection, dynamic validation reveals the flow structure provided by the determination of regional vehicle competence determined in the early stages of new product development. Therefore, the increase in the vehicle projects cost or the extension of the project schedule is fully proportional to the competition gain and market success in the projection [16]. 
The dynamic design verification phase's transitions, which started in the virtual environment, continue at the application site under the physical vehicle road test studies after the completion of the new product development. In the new product projects carried out in the automotive industry, the aim of dynamic vehicle driving tests is to reveal the existence of instantaneous errors under varying driving conditions. Thus, dynamic tests reveal similar values such as driving continuity or range/speed ratio as well as the presence of functional errors in the new vehicle developed during driving. These error sources are monitored and tested with systematic and holistic approaches from system failures to component failures [17].

The successive "static" and "dynamic" design verification phase's transitions in the lean product development process are two complementary approaches. It distinguishes the boundaries of coverage of different disciplines on the new vehicle, rather than being two continuations of design verification techniques, which produce different results against each other. These two techniques, which include the initial and results of the design verification steps that enable the gradual transition in the new vehicle design flow, are used together or consecutively in automotive companies involved in the field study. In addition, dynamic design verification analyses performed under the static design verification approval-control limits applied in the early stages of the lean product development process also update the static design verification parameters. Therefore, functional (performance, lifecycle, safety, etc.) and non-functional product features are also controlled by design verification analysis (static and dynamic), which also enables reviewing, validating, and checking compliance with specifications and standards on innovations on the new vehicle (Figure 4). The virtual static design verification phase's transitions used in the initial stages of the lean product development process provide preliminary control of the suitability of the newly developed vehicle alone to the road conditions or the actual requirements that the customer is not aware of. Thus, while reviewing the physical functioning results of the virtual and dynamic design verification stages transitions, it performs complementary control of virtual and static design verification steps (Figure 4).

As shown in Figure 4, the static and dynamic design verification steps in automotive industry applications are all of the processes that give innovation approval to each stage transition to ensure the results of the design phases of the new vehicle being developed. In addition, the concept of static and dynamic design verification, which is new, has been revealed in field researches that will lead, re-model the lean product development process in the automotive industry in the coming days. With the completion of the computational/software development of all disciplines in the said flow, it was observed in the background of the field study that will accommodate different and new disciplines and create a common ground (Figure 4).

Within the scope of the fieldwork of the research, the current operation determined in practice; after the formation of digital mathematical model of the 


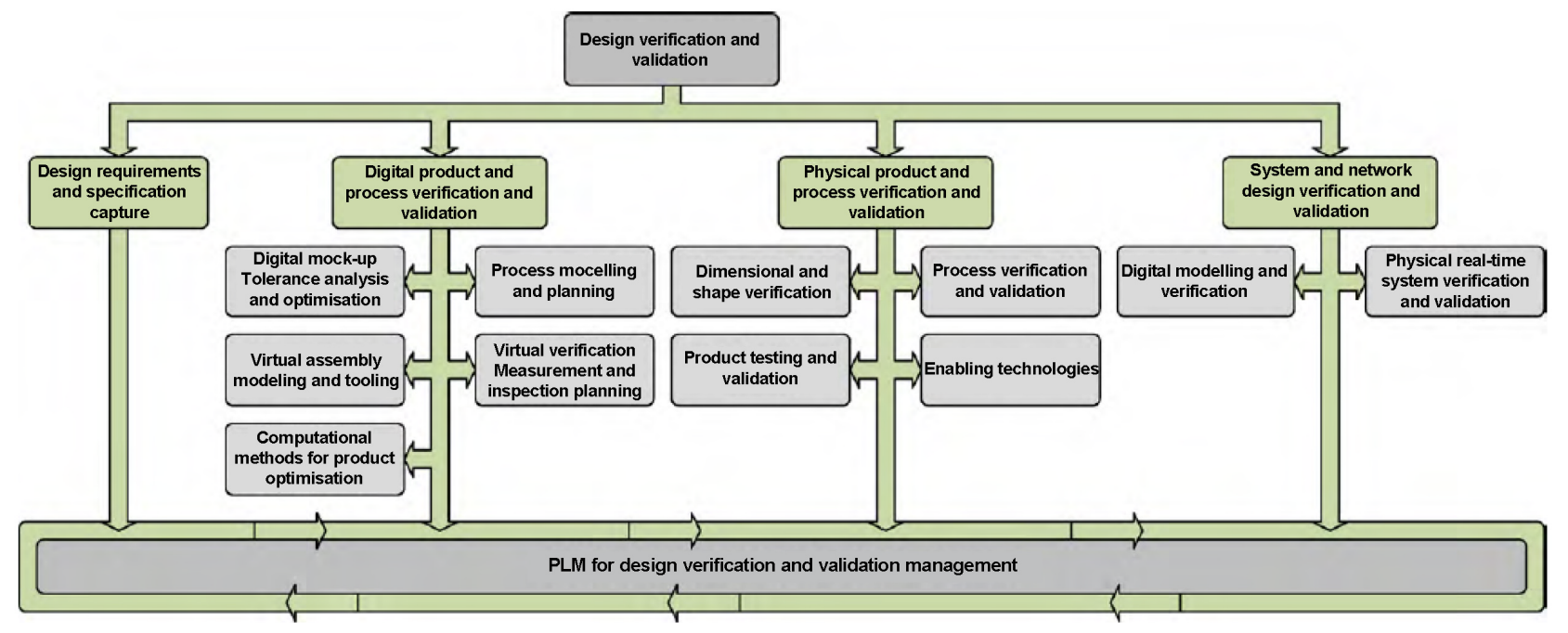

Figure 4. A conceptual framework for design verification phases [1].

new vehicle: virtual static and dynamic design verification testing or analysis: under dynamic accident scenarios, vehicle test forces, virtual error codes are written, or under accident scenarios, the formation of test parameters and the use of virtual tests as a simulation and simulation tool. Furthermore, if we define the purpose of verification of the newly developed vehicle as finding and debugging new or existing system errors, the formation phase of the error remains in the background. Therefore, the use of design verification stages transition analyses under a holistic approach prevents a more complex testing vehicle structure in the development of new products [16]. The purpose of the design verification stage transition analysis in the static and dynamic system is to predict the validation of a particular function or partial structure in the local structure instead of the main vehicle structure. At this point, the purpose is to successfully test the response of the existing or new system (new technology) on the new vehicle, along with its static use, during dynamic driving, defined tolerance parameters, and compatibility with other (new or current, adaptive technology) systems. When analysed with a different approach, the design approach analyses, because the conditions are the diversity of alternative variable scenarios, the aggravation clears the robustness level of the new vehicle. In order to reach this ratio, the limits of working with each other within the main vehicle structure of the new parts, groups and systems on the new vehicle, must be reached. In addition, in the new product development process carried out in the automotive industry, design verification phase's transition analyses provide a parallel flow with the process of introducing new vehicle design.

While the new vehicle meets on a common interdisciplinary denominator, the design verification analyses the parametric structure of the boundary over the limit values of the main system. Static design verification test values, which constitute the initial virtual design phase transitions, constitute the comparison of the existing vehicles or competing products in the product range, and formulate the structure's innovation description and validation values within a plan. It also 
builds dynamic design verification test parameters over static design verification limits, innovation and differences. As important as the design of the new vehicle under the limit values, the static verification, the testing, dynamic verification and tolerance range of the newly developed vehicle under accident scenarios and variable conditions is of great importance. For this reason, the concept of design validation, which is formed by the transition of all disciplines in the new vehicle development stage to the digital computer environment, has been determined in the field researches which are involved in the whole design process and the stage transition analyses are rapidly developing under the need of interdisciplinary testing.

\section{Determination of "Static" and "Dynamic" Design Verification Phases}

In the automotive industry, the process of new and lean product development, in the approval-control of the phase's transitions, the main purpose of the design verification analysis and physical testing analysis is to support the dynamic driving reliability of the vehicle as well as the next development stage of the new vehicle with the expected values. Increasing the driving safety of the automotive industry products, this is the reason for the autonomous driving level of today, started with the transition of virtual vehicle tests to the virtual environment. Initial virtualization, static design verification values, human ergonomics interfacing with vehicle anatomy, static design verification values that intersect the use and integrated function zones of the vehicles.

The new vehicle structure is dynamically tested and analysed in a virtual environment today in the context of dynamic driving responses and driving tolerance values. Therefore, these two types of design verification transition steps values constitute the traceability and limit testing parameters of the new vehicle, together with reviews, along with the life tests of the new parts, groups, systems. Another finding found in field surveys conducted with the employees of the automotive industry firms is the integrated analysis of the effects of newly designed systems and subsystems on the new vehicle developed, as well as the instant traceability, on driving safety.

Figure 5, shows the static design verification steps transition values during the lean product development process common to automotive companies within the scope of field research. In addition to static and dynamic design verification phase's transition analysis, lifecycle, traceability and testing of scope parameters of new functions are reviewed and tested in a virtual environment under possible accident scenarios. In the focus of the dynamic design verification steps transition values, in addition to the vehicle's virtual accident tests, the traceability of the effect of the new functions on active driving and the driving level under the driving safety position are formed. Today, the new vehicle developed in the automotive industry: collision (front, rear, side, pedestrian, etc.), overturning (front-rear approach angle, active-passive safety, etc.), main construction structure, 


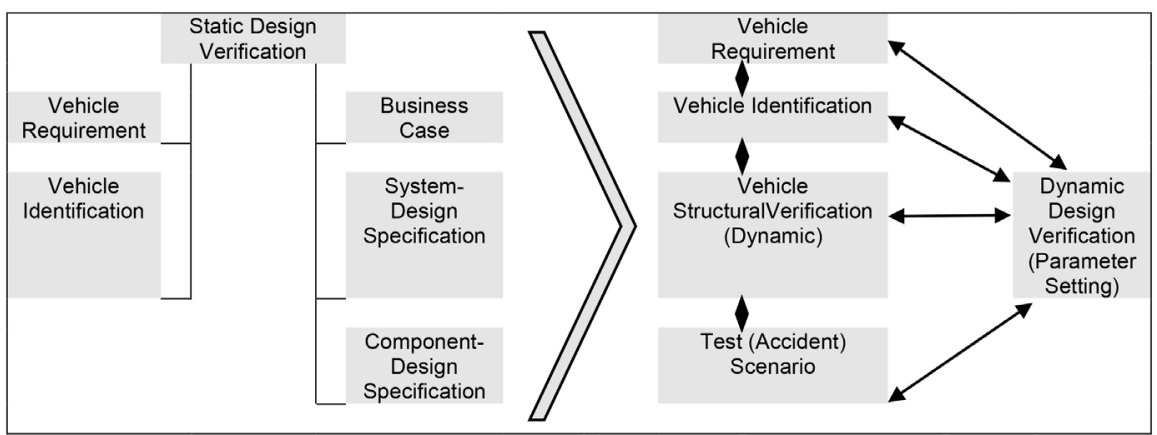

Figure 5. The static and dynamic design verification steps of traceability.

finite element analysis, etc., tests are performed under virtual data vehicle homologation. The automotive companies involved in the research have been analysing the homologations values of the standard international specifications in the new product development process in the virtual environment for the last five years, documenting and presenting the new vehicle to the market. Therefore, the static and dynamic design verification studies in the new product development phase transition, which started with the physical realization of these standard vehicle homologation tests, have now turned into autonomous driving research in a virtual environment under competition. In the lean product development process, while competitively focused customer requirements and value creation are being explored yesterday, today possible accident scenarios drive the entire process for safe autonomous driving. In other approach's, the lean product development process in today's automotive industry: a flow structure in which autonomous vehicle or autonomous driving systems are elaborated, system requirements are established and designs are validated in virtual environment during systematic phase transitions of main and subsystem integrations. The whole lean product development process has been tested in a virtual environment, first static, then dynamically under various accident or alternative driving scenarios, and has developed an integrated process for the continuity of cross-border traceability (Figure 5). In addition, the traceability of the link between the new vehicle and the new system (new technology) and functions established under various accidents or alternative driving scenario predictions reveals the scope of the new functions, together with the structural values of the new vehicle realized during the dynamic design verification phase's transition (Figure 5). For example: within the scope of impact analysis of new functions on the new vehicle developed, safe autonomous driving limit values are reached and with the definition of warning-lower/upper limit measurements, accident scenario combinations where alternative driving situations are matched, first static and then dynamically validation tested. Traceability of test values during the phase transitions of the lean product development process from main vehicle structural development of the vehicle to autonomous driving; the traceability that occurs during the transition from dynamic design verification to static design verification steps is defined as traceability in the reverse direction (Figure $5)$. 
Another important issue in the initial static design verification phase's transitions of the lean product development process is the domains of new functions (technology) or the scope of impact on dynamic driving (value creation). Two types of scope are examined in these static design verification analyses (Figure 5). The new technology of the new function on the vehicle is tested under the scope of the main vehicle structure and the effect on the basic body structure and evaluated in the rate of traceability in the design verification steps.

The effect and scope value of the new function tested in the design verification steps is given in Figure 6, within the framework of traceability ratio. As can be seen in Figure 6, the scope of the variables in the relationship in which the new functions are integrated or influenced by the values that each new function performs in the main vehicle structure is tested. Thus, the initial dynamic test values that are to be monitored are created under the static design validation values of the new function integrated into the new vehicle. In the dynamic design verification transition steps, the scope range of the new functions integrated into the new vehicle design is evaluated together with the driving level and accident test cases, thus effect (parameters) of the newly articulated function on the ride and the operational performance are verified in a virtual environment. The effect (value creation) of the newly articulated function to the basic components it interacts with is developed by testing under all scenarios of alternative driving analysis (Figure 6).

The limits of the new functions, initial static design validation values, which are reached with the dynamic test values created in the next step, are of great importance in the lean product development flow and in the virtual applications (In implementation) of structural vehicle tests (Figure 6). These limit values guide the design verification studies especially during the new product development phase transitions and guide the homologation activities envisaged by the international automotive specifications (Figure 6). In the new product development process observed in the field study realized in automotive industry companies, in addition to design verification testing activities, the control para meters used are reviewed. The purpose of reviewing the new functions of the newly developed vehicle under which test conditions is to determine whether the

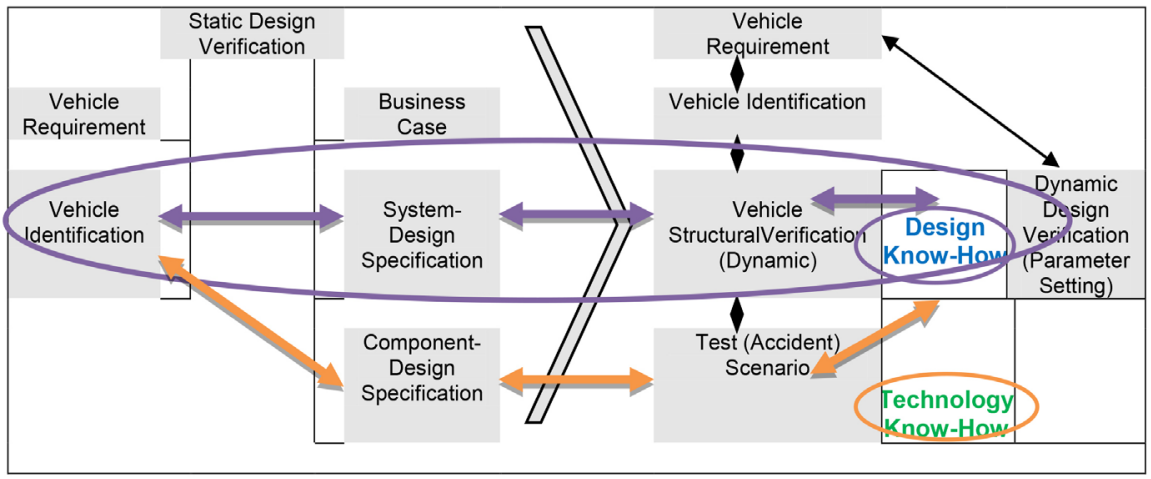

Figure 6. The static and dynamic design verification functions of traceability-scope. 
new functions to be tested are actually verified under the test status or control parameters produced. Thus, it is tried to be ensured that the function of each new function can be verified by the test case that it is sufficient and correct structure.

With these additional inspections in the stage transition of the lean product development process, brought to the design verification steps, all new functions of the new vehicle developed fulfill their functions correctly, if there is no uncontrolled component in the new vehicle other than the intended or the intended new functions are suitable in the state of being controlled by being tested in a main vehicle structure. Furthermore, the testing status of these additional control parameters brought to the design validation step transition steps creates new information for the above mentioned static and dynamic design validation analyses. Thus, the design verification phase transitions are renewed and the test limit values are updated under the test conditions and parameters.

\section{Evaluation of "Static" and "Dynamic" Design Verification Stages}

While the design verification activities taking place in each phase of the new product development process are planned, driving safety studies are carried out in virtual environment from the initial design stages of the vehicle project. Therefore, the test parameters of the new functions in the newly developed vehicle project plans or throughout the entire new product lifecycle, driving dynamics, develop in parallel with the design process. When creating and developing test parameters in design verification passages, potential errors in practice can cause uncontrolled effects of the newly developed vehicle on the structural or driving system. These uncontrolled effects create negative variables to the driving dynamics in the structural and functional systems of the newly developed vehicle, under compliance or non-compliance. For this reason, while creating test parameters in lean product development phase's transitions (in addition to verification and validation activities), the use of various risk analysis techniques has been observed in automotive companies involved in the field study. Therefore, the test parameters allow the development of new main and subsystems by minimizing the effects of any errors or possible errors in the new vehicle systems developed. The limits and scopes of the validations parameters are determined primarily by taking into account the priorities of the new functions in the existing system in active safety and driving dynamics. Therefore, the priority sequence is verified under vehicle integration within the framework of static compliance. This priority level includes the potential risks that may arise in the integration of the driving functions into the interface and the possible risk that the underlying variables may be associated with, or the functional risk analyses in the context of their impact on autonomous driving. The faults are thus classified according to their risk level, as well as their position and priority in driving dynamics. Limits, scope, effects of possible errors of test parameters are 
evaluated by calculating error tree analysis in the priority matrix.

The new vehicle designed during the lean product development phase transitions is tested and evaluated, and when necessary, the design phase is revised and the design changes are modified in order to capture the limit values within the framework of the test plan created under a holistic approach. Thus, even if the likelihood of potential risks occurring during the use of the test parameters cannot be reset, the reduction to an acceptable level under the validation limits would be appropriate for the simplification approach. However, the negative effects of the integrated systems or functions involved in active driving dynamics, error codes, must be examined under predefined risk values and necessary tolerance values should be applied. Figure 7, shows the results of the analysis derived from the AHP mathematical model developed in the study. The risk levels to be used during the test analysis differ according to the design verification system (Figure 7).

In Figure 7, it was determined that the vehicle developed with the design verification structure applied by MB1 automotive company had the highest performance (\%26.7). In addition, as shown in Figure 7, another analysis is the result of the AHP analysis results with a value of \%16.1, although the MB2 automotive company has the highest design time, but has the lowest design validation structure (Figure 7).

\section{Conclusions and Discussion}

As a result, fast-spreading design verification confirmation-control steps, which are the sector in which design, technology and lean process developments are formed and determined, have been compared in detail during field studies. Despite being old in concept and new in application, design verification activities direct and structure the lean product development process that takes place in the automotive industry today. The design verification analyses observed in automotive companies within the scope of the field study are carried out with static test parameters at the beginning of the process, and result in approval-control under dynamic driving and accident scenarios at the end of the flow.

Therefore, if the transition limits between the conversions of static test parameters to dynamic driving safety are correctly defined, new vehicle development flow efficiency and new technology adaptation increase under the simplification of the new product development process (Figure 8).

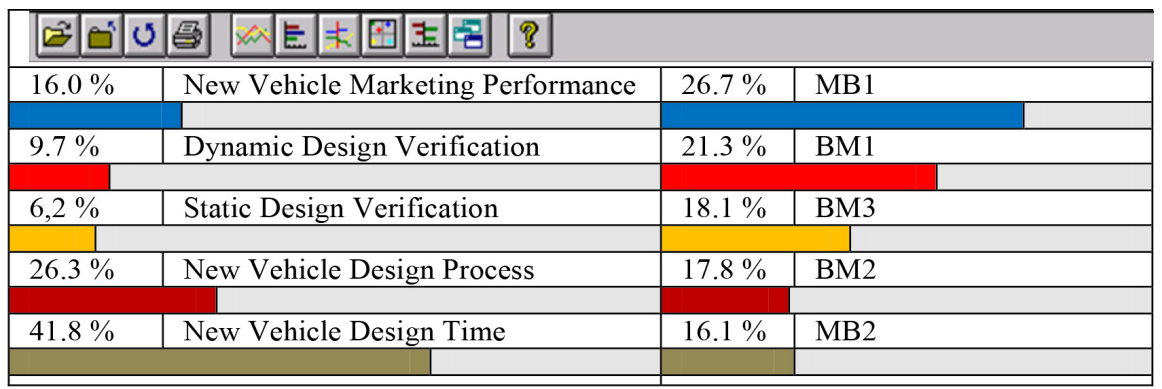

Figure 7. AHP analysis, comparison results chart. 


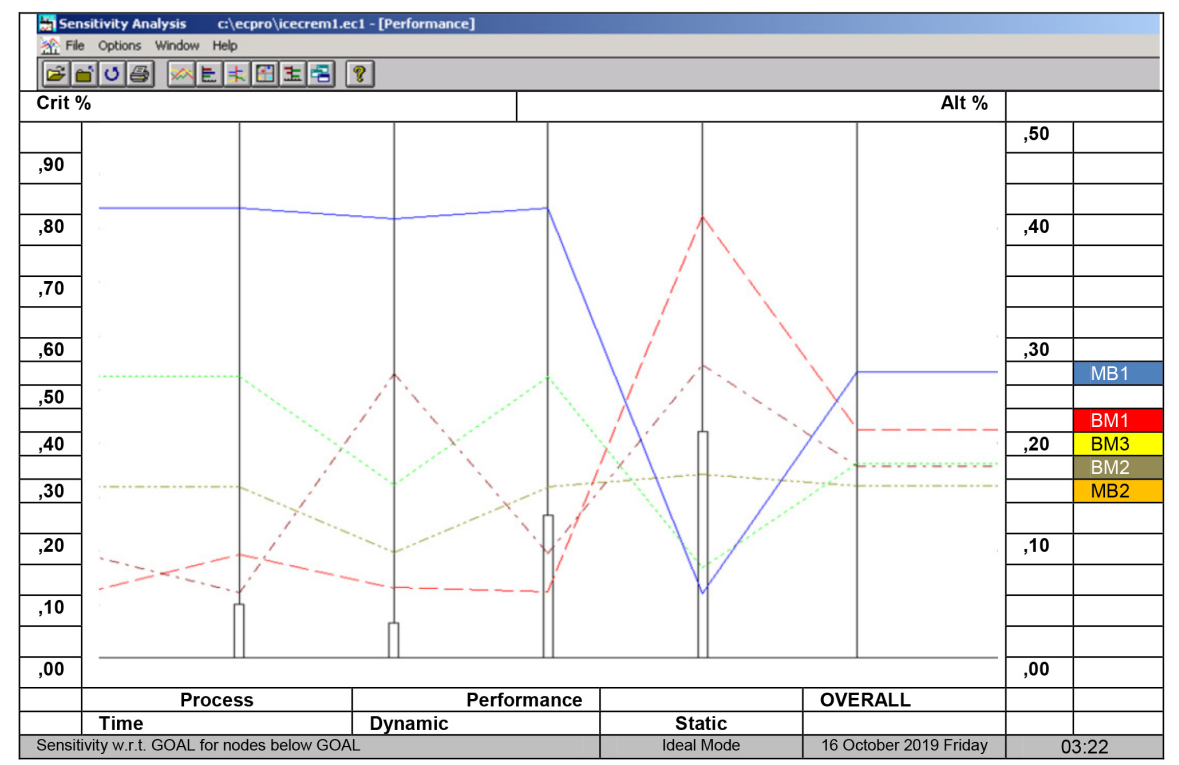

Figure 8. The dynamic analysis result for AHP mathematical model.

According to the results of AHP analysis, MB1, which includes static and dynamic design verification phase transition approvals in the product development process (\%26.7), is also in the first place in the market performance success of the global automotive company (\%16). Accepting international vehicle specifications as static design verification input, BM1 (\%21.3) and BM3 (\%16) were in secondary value in comparison analysis of local automotive companies. MB2 (\%16.1) global automotive company, with low process simplicity and high product development time, ranks last in the same comparison analysis. When AHP comparison analysis conducted under field researches is examined in depth, it is revealed that dynamic design verification stages have a higher impact on market performance than static verification analysis. Therefore, it was determined in the AHP precision analysis given in Figure 8 that the dynamic design verification approval steps (\%9.7) used by BM1 (\%21.3) local automotive company in new product development phase transitions have a direct effect on the market performance success of the new vehicle.

In the study, a process evaluation approach is proposed when the product selection problem is indicated. In addition, the results of AHP application (EC Expert Choice software), which is narrowed down to the stringent priority of an alternative product with adequate development process potential based on the objectives and criteria set in the study, are shared in Figure 8. Figure 8, AHP model shows how to incorporate the development steps that constitute the product in multi-criteria decision criteria in the product selection problem. The effects of the application of the product in Figure 8, AHP result in the priority matrix model and the deviations in the constructed model structure are shown in the scope of the criteria. Within the scope of this study, the positive effect of design verification analysis, which takes place in the new vehicle development phase transitions, which is of great importance in terms of driver, vehicle and 
environment interaction, leads the entire lean product development process.

Furthermore, the signals of the dominance of the validation steps, which constitute the transition values of the lean product development stage, which perform the approval-control and that they will be transformed from autonomous vehicle development to autonomous product development processes have been observed in the field studies.

\section{Conflicts of Interest}

The author declares no conflicts of interest regarding the publication of this paper.

\section{References}

[1] Maropoulos, P. and Ceglarek, D. (2010) Design Verification and Validation in Product Lifecycle. Manufacturing Technology, 598, 740-759. https://doi.org/10.1016/j.cirp.2010.05.005

[2] Chapurlat, V. (2007) Verification et validation de models de systems complexes: Application à la Modélisationd' Entreprise. Université Montpellier II Sciences et Techniques du Languedoc.

[3] Abramovici, M. and Sieg, O. (2002) Status and Development Trends of Product Lifecycle Management Systems. Proceedings of the IPPD, Wroclaw, 1-20.

[4] Denzler, P. and Wiktorsson, M. (2016) Maximising Product Possibilities While Minimising Process Change: A Case of Introducing Light Weight Material in Automotive. Manufacturing Procedia CIRP, 50, 270-274. https://doi.org/10.1016/j.procir.2016.05.033

[5] Geels, F.W. and Penna, C.R. (2015) Societal Problems and Industry Reorientation: Elaborating the Dialectic Issue Life Cycle (DILC) Model and a Case Study of Car Safety in the USA (1900-1995). Research Policy, 44, 67-82. https://doi.org/10.1016/j.respol.2014.09.006

[6] Mariani, F., et al. (2015) Formula-SAE Racing Car: Experimental and Numerical Analysis of the External Aerodynamics. Energy Procedia, 81, 1013-1029. https://doi.org/10.1016/j.egypro.2015.12.111

[7] Matin, M., Hadzistevic, J., Hodolic, D., Vukelic, D. and Lukic, A. (2012) CAD/CAE-Integrated Injection Mold Design System for Plastic Products. International Journal of Advanced Manufacture Technology, 63, 595-607. https://doi.org/10.1007/s00170-012-3926-5

[8] Mclean, E. (1986) Expert Choice, VA: Decision Support Software.

[9] Menter, F.R. (1993) Zona Two Equation km Turbulence Models for Aerodynamic Flows. AIAA Journal, 93, 90-96. https://doi.org/10.2514/6.1993-2906

[10] Menter, F.R. (1994) Two-Equation, Eddy-Viscosity, Turbulence Models for Engineering Applications. AIAA Journal, 32, 1598-1605. https://doi.org/10.2514/3.12149

[11] Menter, F.R., Kuntz, M. and Langtry, R. (2013) Ten Years of Industrial Experience with the SST Turbulence Model. Turbulence Heat and Mass Transfer, 20, 13-20.

[12] Muita, K., Westerlund, M. and Rajala, R. (2015) The Evolution of Rapid Production: How to Adopt Novel Manufacturing Technology. IFAC-Papers Online, 48, 32-37. https://doi.org/10.1016/j.ifacol.2015.06.054

[13] Remiel, F.M., Cauvin, A. and Ferrrarini, A. (2015) Verification of Design Rules as 
an Evaluation Method during the Reconfiguration Process of Production Systems. IFAC-Papers Online, 48, 1676-1681. https://doi.org/10.1016/j.ifacol.2015.06.327

[14] Ullah, I., Tang, D. and Yin, L. (2016) Engineering Product and Process Design Changes. A Literature Overview. Procedia CIRP, 56, 25-33.

https://doi.org/10.1016/j.procir.2016.10.010

[15] Whyte, J., Stasis, A. and Lindkvist, C. (2015) Managing Change in the Delivery of Complex Projects: Configuration Management, Asset Information and "Big Data". International Journal of Project Management, 34, 339-351.

https://doi.org/10.1016/j.ijproman.2015.02.006

[16] SAE Aerospace ARP4754a (2009) Aerospace Recommended Practice.

[17] Pickering, S.G. and Brace, C.J. (2007) Automated Data Processing and Metric Generation for Drive Ability Analysis. Proceedings of Mechanical Part Journal of Automobile Engineering, 221, 429-441. https://doi.org/10.1243/09544070JAUTO347 